\title{
Numerical Simulation of the Influence of Nozzle on the Variable Load Performance of Premixed Burner
}

\author{
Guangpeng $\mathrm{LI}^{1,2, \mathrm{a}}$, Hengchao ZHOU ${ }^{1, \mathrm{~b}}$, Qi WANG ${ }^{1, \mathrm{c}}$, Bin $\mathrm{LI}^{1, \mathrm{~d}}$ \\ ${ }^{1}$ Schooo of Electromechanical and Automotive, Shandong Institute of Commerce and Technology, \\ Jinan, China \\ ${ }^{2}$ School of Mines, China University of Mining and Technology, Xuzhou, China

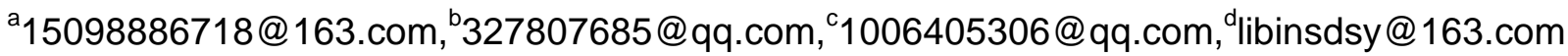

Key words: Nozzle; Premixed burner; Numerical Simulation

Abstract. In order to estimate the influence of various parameters of the nozzle on the premixed burner, the main technical parameters of the premixed burner nozzle were investigated by numerical simulation method. The factors including depth of the nozzle, back pressure of mixing chamber, outlet velocity were studied. By analyzing the case, the results show that the gas flow and velocity of different depth nozzles vary greatly, and the nozzle flow rate and the average speed of exit are all reduced with the mixing chamber pressure increased. In addition, the results show that the flow rate calculated by conventional method cannot reflect the actual situation of gas and air mixing.

\section{Introduction}

The gas nozzle is one of the key components of premix burners. It uses the jet of turbulent diffusion, to a certain extent, mixed with two different pressure fluids. The design of traditional burner nozzle relies mainly on empirical equations. The nozzle flow is generally calculated according to $L_{g}=0.0035 \mu d^{2} \sqrt{\frac{H}{S}}$ and the flow factor $\mu$ needs to be empirically determined (usually $\mu$ chooses $0.75)[1,2]$. Due to the limitations of the test methods and methods, it is necessary to repeatedly test and correct the flow field inside the combustor for different real conditions and detailed information.

The main technical parameters of the nozzle are nozzle diameter, gas pressure before the nozzle, nozzle depth and pressure in the mixing chamber. They all have an influence on the nozzle gas flow and the velocity distribution of the nozzle exit. For variable load burners, it is by changing the pressure of the nozzle before the gas to achieve. The depth of the nozzle affects the flow rate and nozzle exit velocity. The nozzle outflow velocity determines the jet range of the gas jet, which is one of the key parameters for gas and air mixture. Common nozzles are typically gas injection into the atmosphere, the premixed burner mentioned in this article is a positive pressure mixing chamber, which will inevitably have an impact on gas flow. In this paper, FLUENT12 software was used to establish the fluid mechanics model of the nozzle of the premixed combustor, and to analyze the complex flow phenomena such as turbulence and multi-component diffusion in the combustor under different working conditions. The main performance parameters of the nozzle were determined and the experiment Verify, provide a powerful reference for the burner optimization design.

\section{Geometry and boundary conditions}

The geometric model. The working fluid is methane. The excess air coefficient is 1.05 , and the variation range of gas pressure is from $800 \mathrm{~Pa}$ to $2800 \mathrm{~Pa}$. The nozzle diagram is shown in figure 1 . 


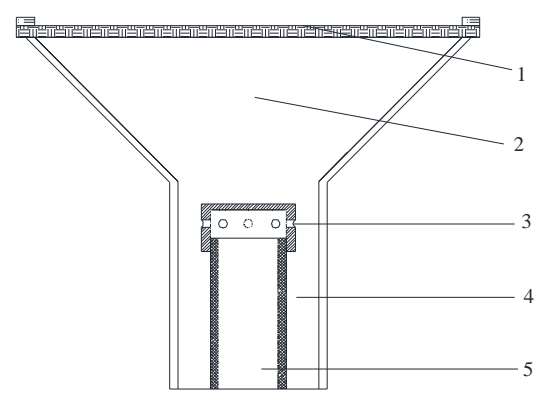

Fig.1 Schematic diagram of burner nozzle.

1, Metal fiber burning surface; 2, Burner head; 3, Nozzle; 4, The air pipe; 5, The gas pipe

Analog computing area. In this paper, the one nozzle is used as the research object, and the calculation region is shown in figure 2 , which consists of a nozzle with a diameter of $1 \mathrm{~mm}$ and a lengthening segment with a diameter of 5 times nozzle before and after the nozzle, respectively as the inlet section of gas pressure and the pressure outlet section. The grid adopts hexahedral mesh and is used to encrypt the internal nozzle to improve the accuracy and reliability of flow simulation.

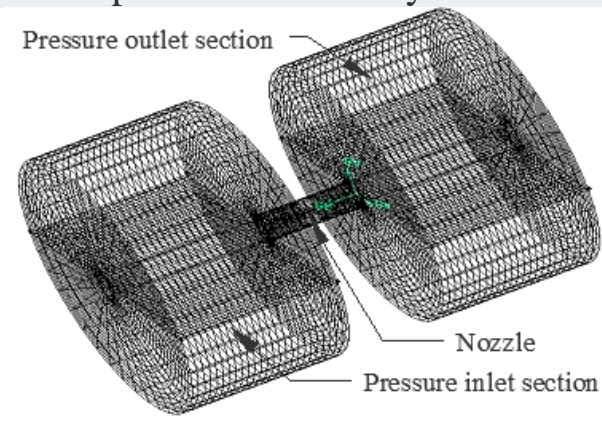

Fig.2 The nozzle simulation calculation area

Turbulence model and boundary conditions. The fluid flow and different components (the mixing between gas and air) belongs to the turbulent diffusion problem [3]. The RNG model is adopted to solve the problem, and the wall velocity boundary layer is strengthened by using the enhanced wall function. To simplify the practical problems, the following assumptions were made before establishing the mathematical model. Gas and air meet the law of internal friction and belongs to Newtonian fluid. The fluid is mixed at room temperature and the density is regarded as constant. Due to low pressure, it can be considered as incompressible fluid. The flow of gas and air belong to steady state turbulence.

Pressure boundary conditions are used to define the total pressure or static pressure of flow inlet and outlet[4]. The gas inlet is the pressure inlet boundary type, the volume fraction of the material component methane is $100 \%$. The gas outlet is the pressure outlet, instead of the free flow boundary, in order to simulate the actual gas injection into the positive pressure mixing chamber, and the simulated pressure outlet is $50 \mathrm{~Pa}$. Other boundary conditions are wall.

\section{Simulation results and discussion}

The relationship between nozzle pressure and gas flow in different nozzle depth. Fig. 3 and 4 show the relationship between gas pressure and gas flow rate and average outlet speed of gas at different nozzle depths. It can be seen that the calculation formula of nozzle flow is very different from that of simulation value. The simulation results show that the average velocity of gas flow and gas outlet is not linear with the gas pressure, and the gas flow and velocity of different depth nozzles vary greatly under the same gas pressure. The flow rate of the nozzle with depth of $2 \mathrm{~mm}$ and $3 \mathrm{~mm}$ is about $2-5 \%$, and the export speed difference is $0.6-1.5 \mathrm{~m} / \mathrm{s}$. In the design scheme, the nozzle with a diameter of $1 \mathrm{~mm}$ and depth of $3 \mathrm{~mm}$ is adjusted. The experimental results and the simulation results are within $4.5 \%$, but the variation trend is the same as the simulation. The model can provide design basis for simulating other diameters and depth nozzles, such as nozzle flow and the average outlet velocity. 


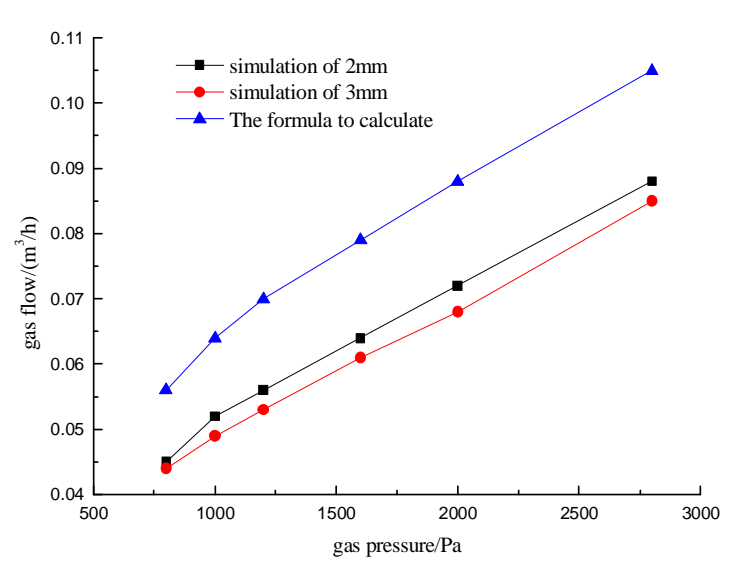

Fig.3 The relationship between nozzle pressure and gas flow in different nozzle depth

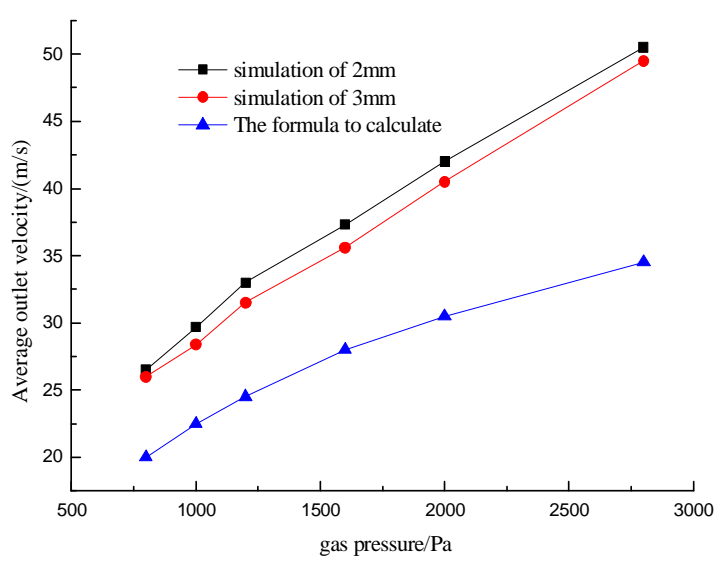

Fig.4 The relationship between gas pressure and average outlet velocity under different nozzle depth

The influence of mixing chamber back pressure on nozzle flow rate and average outlet velocity. Because the burner is a positive pressure mixed combustion, the mixing chamber pressure has a certain influence on the nozzle flow rate and the outlet speed. Fig. 5 and 6 are the effects of the back pressure of different mixing rooms on the nozzle flow and average exit velocity. It can be seen that the mixing chamber pressure is increased, the nozzle flow rate and the average velocity of the outlet are all reduced. In the figure, $\mathrm{P}_{\mathrm{in}}=2000 \mathrm{~Pa}$ indicates that the gas inlet pressure is constant at $2000 \mathrm{~Pa}$, while the mixed chamber pressure changes. $\mathrm{P}_{\text {mixture }}=0 \mathrm{~Pa}$ indicates that the inlet pressure changes and the mixing chamber pressure is zero, but the pressure difference is the same as that of the back pressure. It can be seen that both conditions have little impact on gas flow and export speed, both within $2 \%$. Therefore, the change of back pressure can be reduced to the change of inlet pressure.

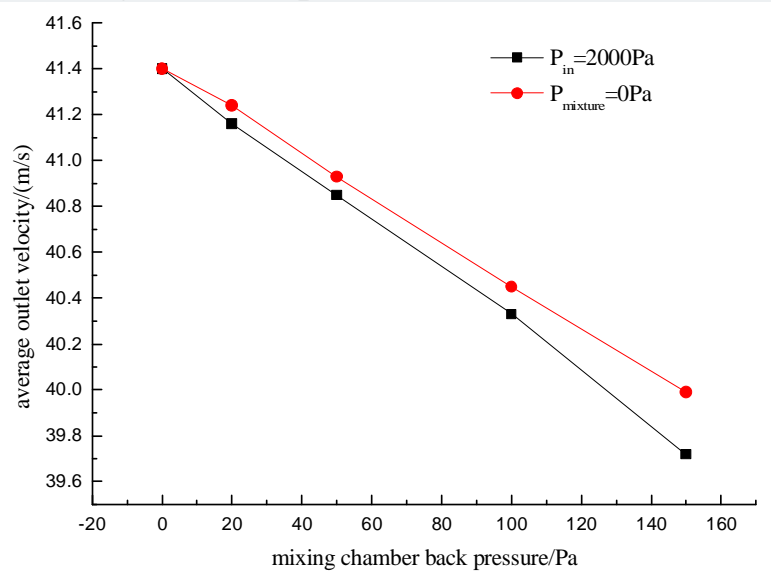

Fig.5 Influence of mixing chamber back pressure on average outlet flow velocity

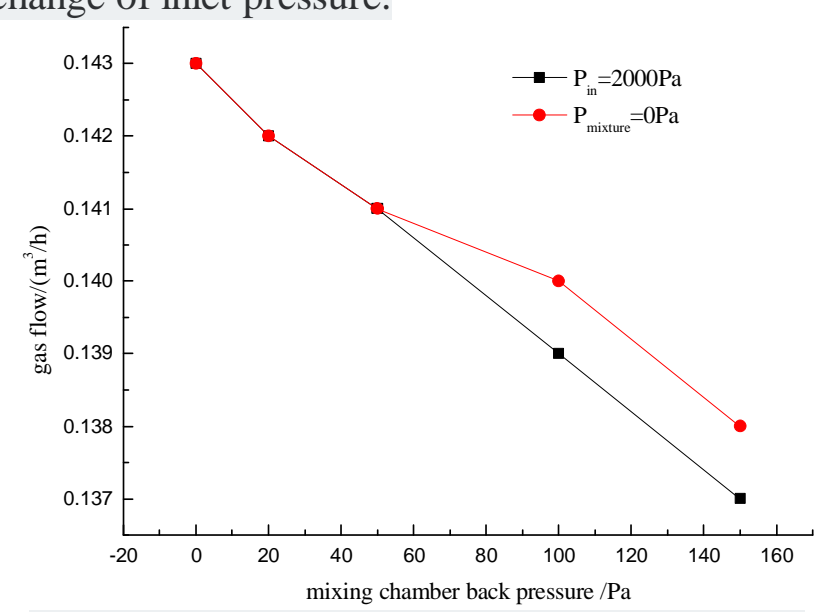

Fig.6 Influence of mixing chamber back pressure on gas flow

Velocity distribution of nozzle outlet. A mixture of gas and air is a gas at high speed jet rushed into the vortex in the air, the range of gas jet decide the width of the air flow channel mixer, so the design must understand the velocity and distribution of gas in the nozzle outlet. The conventional gas velocity calculation method is the volume flow of the unit area. Fig 7 is the gas outlet velocity under different pressure, and the three speed lines respectively represent the conventional speed, average speed and maximum speed. The simulation results show that the maximum velocity is $62 \mathrm{~m} / \mathrm{s}$ and $33 \mathrm{~m} / \mathrm{s}$ respectively. The average exit velocity is $50 \mathrm{~m} / \mathrm{s}$ and $26 \mathrm{~m} / \mathrm{s}$, while the conventional calculation speed is $32 \mathrm{~m} / \mathrm{s}$ and $17 \mathrm{~m} / \mathrm{s}$ respectively. It can be seen from the comparison that the speed difference between the two is large, and the flow rate calculated by conventional method cannot reflect the actual situation of gas and air mixing. 


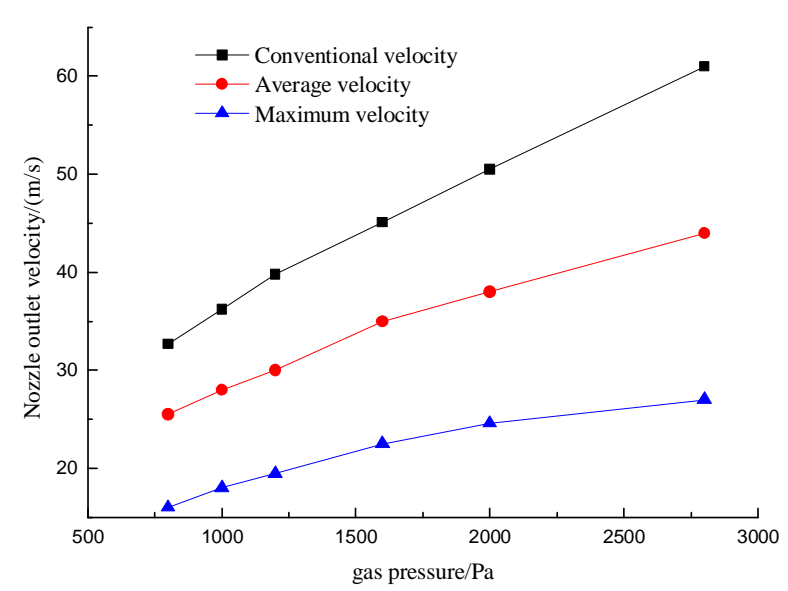

Fig.7 Nozzle outlet velocity under different gas pressure

\section{Conclusions}

Under the same gas pressure, the gas flow and velocity of different depth nozzles vary greatly. The flow rate of the nozzle with a depth of $2 \mathrm{~mm}$ and $3 \mathrm{~mm}$ is about $2-5 \%$, and the export speed difference is $0.6-1.5 \mathrm{~m} / \mathrm{s}$. The mixing chamber pressure is increased, the nozzle flow rate and the average speed of exit are all reduced. The gas outlet velocity is different, and the flow rate calculated by conventional method cannot reflect the actual situation of gas and air mixing.

\section{Reference}

[1] Yuanyuan FANG, Quan GUO. Numerical Simulation of Influence of Nozzle Position on Injector Performance[J]. GAS and HEAT, 2007, 27(7):42-44.

[2] Darong YAO. Study on full premixed combustion characteristics of gas and commercial combustion tools[D]. Beijing University of Civil Engineering and Architecture, 2002.53-54.

[3] Leopardi S.A. Viskanta R. Gore J.P. Analytical and experimental study of combustion and heat transfer in submerged flame metal fiber burners/heaters. Journal of Heat Transfer, 2003, Vol. 125(1):118 125.

[4] Bouma-PH; De-Goey-LPH, Premixed Combustion on Ceramic Foam Burners, Combustion and Flame,1999, Vol.119(1):133-143. 